\title{
TOTAL COLUMN OZONE AND SOLAR UV-B ERYTHEMAL IRRADIANCE OVER KISHINEV, MOLDOVA
}

\author{
A.A. ACULININ
}

\author{
Atmospheric Research Group (ARG) \\ Institute of Applied Physics \\ Academy of Sciences of Moldova \\ 5 Academiei Str., Kishinev, MD-2028, Moldova
}

Received: $15 / 12 / 05$

Accepted: 02/05/06 *to whom all correspondence should be addressed: e-mail: akulinin@phys.asm.md

\section{ABSTRACT}

Results of the total column ozone and ultraviolet (UV-B) erythemally weighted irradiance measurements at the ground-based solar monitoring station at the Kishinev (Moldova) are presented. Diffuse and global components of solar UV-B erythemal irradiance on horizontal plane were continuously measured with sensors UV-S-B-C (of broadband 280-315 nm), Kipp\&Zonen. Monthly totals of global and diffuse components of solar UV-B erythemal radiation reveal distinct seasonal variation with respective minimum in winter and maximum in summer. Typical values for these components in limiting cases are presented. A simple polynomial relationship between the global and diffuse components of solar UV-B erythemal radiation measured for cloudless days was derived. It was shown that coefficients of the polynomial depend on daily mean value of aerosol optical thickness (AOT). Collocated measurements of AOT have been carried out with the sunphotometer Cimel CE-318 within the framework of the Aerosol Robotic Network (AERONET) program, managed by NASA/GSFC.

Total column ozone content was retrieved from direct solar ultraviolet radiation measurements at 3 discrete wavelengths centered at 305.5, 312.5, and $320 \mathrm{~nm}$ within the UV-B range. Ozone measurements were regularly carried out with the hand-held MICROTOPS II Ozonemeter, Solar Light Co. Monthly average values of total column ozone content measured with the MICROTOPS II at the Kishinev are in close agreement with those ones retrieved from the multiyear (1978-2004) database statistics acquired from satellite platforms measurements with the Total Ozone Mapping Spectrometer (TOMS). It was shown the existence of seasonal variability of the total column ozone content with respective minimum values observed at the end of autumn and winter, and maximum values observed at the end of winter and in spring. The maximum and minimum of daily mean values of total column ozone ever measured with TOMS at the satellite platforms overpassed Kishinev site, amounted of $\sim 540$ DU (on February 19, 1985) and 204 DU (on December 1, 1999). Yearly mean value of total column ozone measured at the Kishinev was $\sim 338$ DU. Total column ozone measurements carried out with MICROTOPS at the Kishinev site from September 2003 to August 2004, gave maximum and minimum values of ozone daily means at $\sim 489$ DU (on February 12, 2004) and 259 DU (on December 3, 2003). The estimation of total column ozone trend derived from the TOMS multi-year statistics was $\sim-10$ DU/decade.

KEYWORDS: column ozone content, UV-B erythemal radiation, aerosol optical thickness.

\section{INTRODUCTION}

Ozone and aerosol particles in atmosphere modify the intensity and spectral composition of the solar ultraviolet radiation at the Earth's surface. Each of components has a specific influence upon the radiation exchange and interaction processes that finally define of solar UV-B radiation reaching the surface. Aerosols produced by both human activities and natural processes affect the UV-B radiation within the whole atmosphere through the scattering and 
absorption processes. The absorption of the UV-B radiation is largely controlled by ozone in the stratosphere at altitudes between 25 and $100 \mathrm{~km}$. There are, however, other effects that influence the UV-B radiation transfer: cloud cover, tropospheric ozone, other gaseous pollutions, surface albedo. To investigate complex relationships between various phenomena taking place in the atmosphere it is necessary to have reliable total column ozone and solar UV-B radiation data obtained from the ground-based measurements. As a consequence of ozone and aerosols can change the UV-B exposure both locally and globally, ground-based solar radiation monitoring stations become of a particular of interest to obtain an exhaustive and reliable continuous flow of information about the resulting UV-B erythemal radiation field on the Earth's surface and the total column ozone content at the sites of observation.

This paper discusses results of the total column ozone and solar broadband ultraviolet (UV-B) erythemal weighted irradiance measurements carried out at the ground-based solar monitoring station at the Kishinev, Moldova.

\section{MEASUREMENT APPROACH}

For the first time in Moldova it was established ground-based station for continuous solar radiation monitoring. Station was equipped with the solar radiation sensors for broadband measurements of radiation from UV-B to IR, data logger CR10X, and active solar tracker unit 2AP BD, (Kipp\&Zonen). These instruments were assembled into the multifunctional radiometric complex. Additional instruments, such as an automatic weather station MiniMet, ozonemeter MICROTOPS II and sunphotometer Cimel CE-318, are used at the station. Data sets collected from weather station MiniMet (Sky Instruments Ltd.), which is arranged at a distance of 30 meters apart from the radiometric measuring complex, supplement the solar radiation measurements. Radiometric complex is placed in an urban environment at the Kishinev site (see Fig. 1) with coordinates: $\varphi=47.0013^{0} \mathrm{~N}, \quad \lambda_{0}=28.8156^{0} \mathrm{E}, \mathrm{h}=205 \mathrm{~m}$ a.s.l. All instrumentation was mounted on the roof of the building of the Institute of Applied Physics, Academy of Sciences of Moldova.

Radiometric complex is used to carry out long-term continuous monitoring of solar radiation at the Earth's surface. Measurements are made with $1 \mathrm{sec}$ resolution and 1 minute averaging interval. Solar radiation sensors used at the station allows for covering wavelength range from UV-B to IR and to make broadband measurements of global, diffuse and direct components of solar radiation. Diffuse and global components of the solar UV-B irradiance are measured with two sensors UV-S-B-C (of broadband $280-315 \mathrm{~nm}$ ) installed at the moving platform of the active solar tracker 2AP BD unit and mounted at the stationary platform, respectively. Solar UV-B erythemal weighted irradiance is re-calculated by using the specific adjustment tables for each sensors taking into account the solar zenith angle and total column ozone content at the site of observation.

Typical values of measured global and diffuse components of monthly totals of solar UV-B erythemal radiation are presented. Total column ozone content is regularly measured at the station by hand-held narrowband filter MICROTOPS II Ozonemeter, (Solar Light Co) [1]. This instrument is equipped with the highest grade and long stability filters with ion-beam assisted deposition and centered at $\lambda=305.5,312.5320,936 \& 1020 \mathrm{~nm}$. MICROTOPS II Ozonemeter gives an accuracy $<2 \%$ for total ozone measurements made by much larger and more expensive instruments, such as Dobson and Brewer spectrophotometers. Total column ozone content is retrieved from the simultaneous measurements of direct solar ultraviolet radiation at 3 discrete wavelengths centered at 305.5, 312.5, and $320 \mathrm{~nm}$ with $2.4 \mathrm{~nm}$ (FWHM) band pass for these channels within UV-B range. Due to portability, mobility and possibility to make fast measurements of the total column ozone, the ozonemeter can be successfully used for measurements in conditions of broken clouds. Principally, the measurements of the total column ozone are carried out in solar culmination (in midday hours) when the air mass reaches it small value or during the hours with an appropriate weather conditions, e.g., in the presence of broken clouds. MICROTOPS II Ozonemeter allows for making reliable measurements of the total column ozone for air masses up to values $\sim 3-3,5$ (AM and PM).

Sunphotometer Cimel CE-318 makes measurements of the direct Sun and diffuse sky spectral radiances to retrieve aerosol optical properties. Instrument carries out direct Sun 
measurements at seven spectral channels $\lambda=340,380,440,500,670,870$, and $1020 \mathrm{~nm}$. Uncertainty in AOT $\tau_{a}(\lambda)$ measurements consists of value $\delta \tau_{a}(\lambda)=0.01-0.02$. Measurements of the sky radiance (in almucantar and principal plane) are made at four spectral channels within the spectral range from 440 to $1020 \mathrm{~nm}$. More detailed instrument specification, measurement sequences, data quality control and accuracy procedures are described in [2-4]. Sunphotometer works within the framework of the Aerosol Robotic Network (AERONET) program, managed by NASA/GSFC [2].

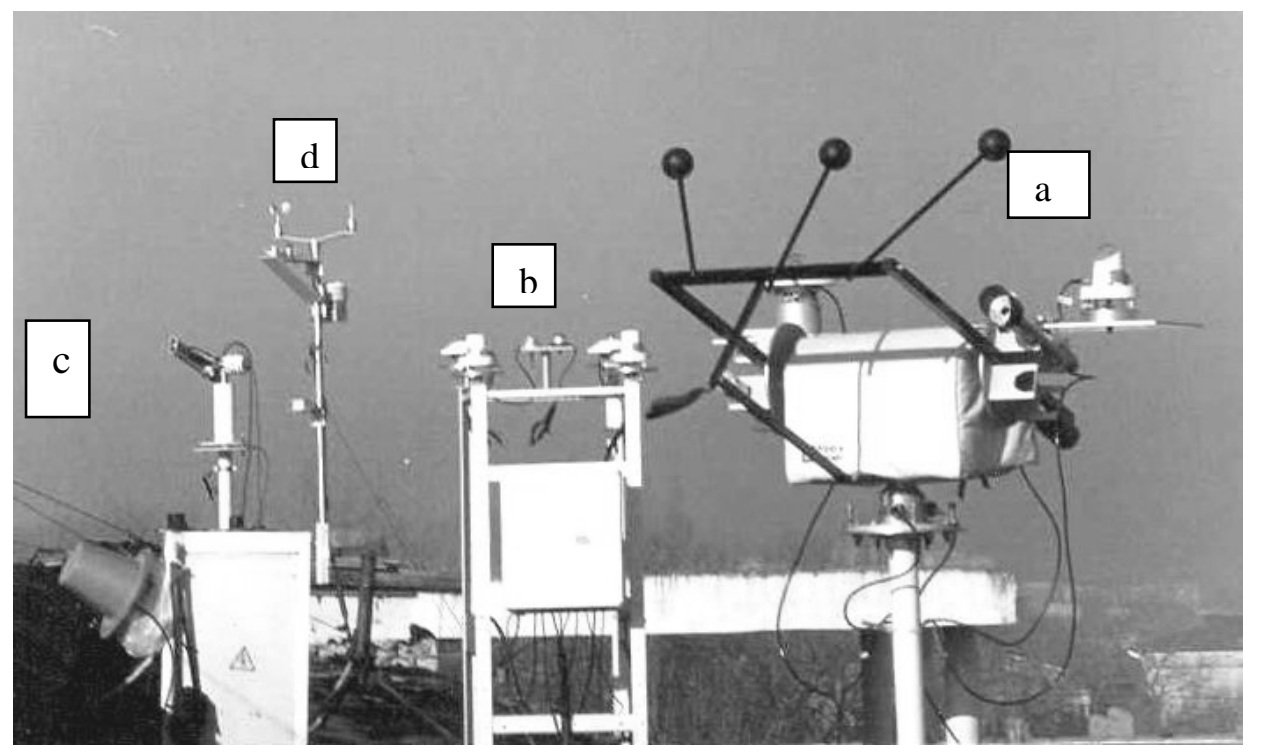

Figure 1. Ground-based solar radiation monitoring station in operation at the Kishinev site. Solar station consists of radiometric complex with moving (a) and stationary (b) platforms, sunphotometer Cimel CE-318(c) and automatic weather station MiniMet (d).

\section{RESULTS}

Since the October 2003, solar radiation measurements from UV-B to IR have been continuously carrying out at the solar radiation monitoring station established at the Kishinev site. Period of observation was chosen from October 2003 to September 2004. Regular measurements of the total column ozone were started from July 2003.

Monthly totals of global $\Sigma_{M} Q_{U V B}$ and diffuse $\Sigma_{M} D_{U V B}$ components of solar UV-B erythemal radiation on horizontal plane are shown in Figure 2.

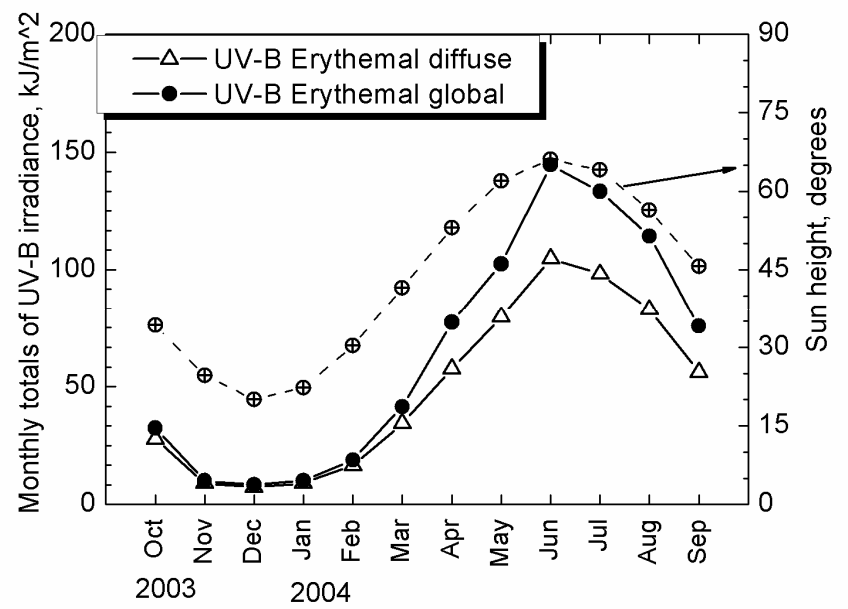

Figure 2. Variation of the monthly totals of global and diffuse solar UV-B erythemal radiation (on horizontal plane) at the Kishinev site 
UV-B radiation was measured with two UV-S-B-C sensors from Kipp\&Zonen. For measured global and diffuse components of monthly totals of solar UV-B erythemal radiation it was shown the existence of distinct minimum and maximum of values. $\Sigma_{M} Q_{U V B}$ and $\Sigma_{M} D_{U V B}$ components reached the minimum on December with respective values of $\Sigma_{M} Q_{U V B}=8.5 \mathrm{~kJ} / \mathrm{m}^{2}$ and $\Sigma_{M} D_{U V B}=7.4 \mathrm{~kJ} / \mathrm{m}^{2}$. Maximum values for these components were registered on June with respective values, $\Sigma_{M} Q_{U V B}=144.5 \mathrm{~kJ} / \mathrm{m}^{2}$ and $\Sigma_{M} D_{U V B}=104.7 \mathrm{~kJ} / \mathrm{m}^{2}$. One of the reasons of the minimum existence, typical both for $\Sigma_{M} Q_{U V B}$ and $\Sigma_{M} D_{U V B}$, was due to the low height of the Sun $h_{0}$ above the horizon during the months of November and December, when $h_{0}$ reached minimum value of $\sim 20^{\circ}$. Naturally, occurrence the maximum value for $\Sigma_{M} Q_{U V B}$ and $\Sigma_{M} D_{u v B}$ components was due to the maximum value of the Sun height, $h_{0} \sim 66^{\circ}$, which corresponded to June-July period. Another reason of the existence of these extreme is connected with the influence of the meteorological conditions. Meanwhile the absolute values of monthly totals of solar radiation and sunshine duration are mainly defined by clouds cover (e.g., by cloudy factor or number of overcast days) at the site of observations. To imagine the influence of cloudness upon the measured UV-B irradiances, it was analyzed the scattergram of average values of global QuvB versus diffuse DuvB components of the solar UV-B erythemal irradiances for two extreme cases: cloud free and overcast days. For example, these UV-B erythemal irradiance components were measured for selected cloud free day on September 6, 2004 and final form of the scattergram is shown on Figure 3. For cloud free days the simple regression relation for the scattergram is given as

$\mathrm{Y}=\mathrm{C}+\mathrm{AX}+\mathrm{B} \mathrm{X}^{2}$

where $C<<1, Y \equiv Q_{U V B}$ and $X \equiv D_{U V B}$ are global and diffuse components of the solar UV-B erythemal irradiances, respectively. Coefficients $A$ and $B$ depend on daily mean value of aerosol optical thickness (AOT) $<T_{a}(500)>$ measured with the sunphotometer Cimel CE-318 at $\lambda=500 \mathrm{~nm}$ (see Figure 4). Coefficient $A$ has a little dependence on $\left\langle T_{a}(500)\right\rangle$ and mean value of $\langle A\rangle$ is $\sim 1.1$, whereas coefficient $B$ has strong dependence on $\left\langle T_{a}(500)\right\rangle$. Coefficient $B$ decreases with the increase of $A O T<T_{a}(500)>$. For the set of clear free days these scattergrams have the analogous dependence, but with specific $A$ and $B$ coefficients. For overcast days coefficient A tends to be equal to the ratio QuvB / $D_{U V B} \sim 1.07$ and coefficient B becomes equal to 0.0 .



Figure 3. Scattergram of minute average values of global vs. diffuse components of the solar UV-B erythemal irradiances for cloud free day on September 6, 2004.

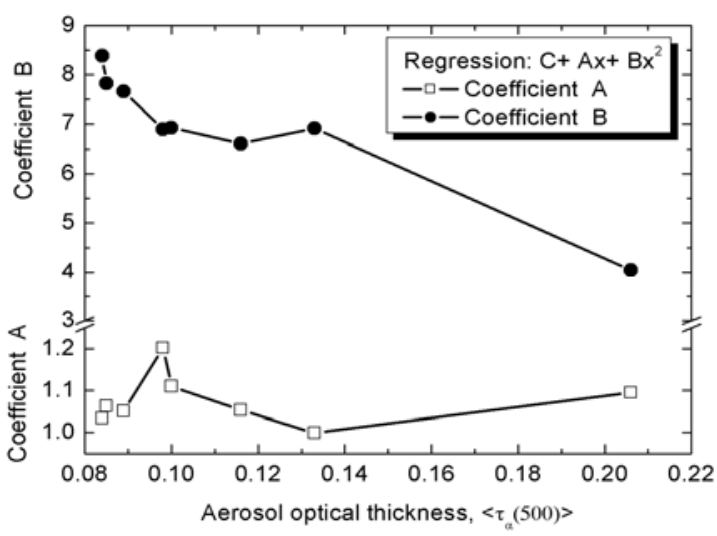

Figure 4. Variation of coefficients $A$ and $B$ versus daily means of aerosol optical thickness $<\mathrm{T}_{a}(500)>$ at $\lambda=500 \mathrm{~nm}$ for selected cloud free days from April to September 2004.

Figure 5 shows monthly average values of total column ozone content retrieved from multiyear (1978-2004) statistics retrieved from TOMS measurements and measured with hand-held MICROTOPS II ozonemeter at the Kishinev site during September 2003 - August 2004. It is clear seen the existence of seasonal variability of total column ozone content with minimum observed at the end of autumn and in winter, and maximum observed at the end of winter and in spring. Ozone values obtained from measurements made with MICROTOPS 
and retrieved from TOMS measurements are in good agreement with each other. The most scatter in the data measured with MICROTOPS was observed from December to March. The error bars show one standard deviation. Figure 6 shows multiyear (1978-2004) statistics of the yearly average values of total column ozone content retrieved for the Kishinev site from the measurements made at the satellite platforms with the TOMS.



Figure 5. Monthly average values of total column ozone content retrieved from multiyear (1978-2004) statistics from TOMS measurements and measured with hand-held MICROTOPS II at the Kishinev site during September 2003 - August 2004.

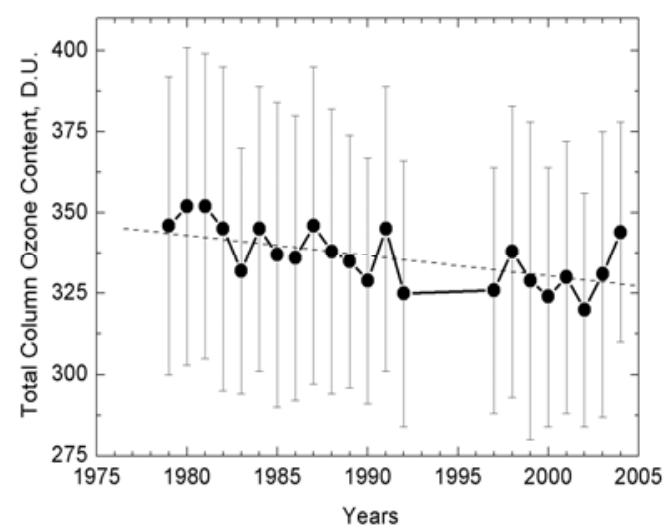

Figure 6. Multiyear (1978-2004) statistics of the yearly average values of total column ozone content retrieved from measurements made with TOMS at the satellite platforms overpassed Kishinev site.

The maximum and minimum of daily mean values of total column ozone ever measured with TOMS from satellite platform overpassed Kishinev site, amounted of $\sim 540$ DU (on February 19, 1985) and 204 DU (on December 1, 1999), respectively. The last extreme value of column ozone content is attributed to the mini ozone holes evolution over the West and Central Europe in December 1999. The estimation of total column ozone trend gives the value of $\sim-10 \mathrm{DU} /$ decade. Total column ozone measurements carried out with MICROTOPS at the Kishinev site from September 2003 to August 2004, gave maximum and minimum values of ozone daily means at $\sim 489$ DU (on February 12, 2004) and 259 DU (on December 3,2003 ), respectively. Yearly mean values of the total column ozone content derived from ground-based measurements at the Kishinev site and retrieved from the multiyear statistics of the TOMS measurements were very close to each other and gave the values of $\sim 338 \mathrm{DU}$ and $\sim 334 \mathrm{DU}$, respectively.

\section{CONCLUSIONS}

Continuous solar radiation measurements from UV-B to IR have been carrying out at the solar radiation monitoring station established in an urban environment of Kishinev. Period of observation was chosen from October 2003 to September 2004. Results of measurements of the monthly totals of global and diffuse components of solar UV-B erythemal radiation (with UV-S-B-C sensors of broadband $280-315 \mathrm{~nm}$ ) on horizontal plane are presented. It was shown seasonal variation of these components with the presence of minimum (for winter season) and maximum (for summer) of their values. It was shown the influence of the number of overcast days upon the variation of the monthly totals of sunshine duration. The regression relationship of the scattergram for global QuvB and diffuse $D_{U V B}$ components of solar UV-B erythemal radiation measured for cloud free days may be represented by second order polynomial regression curve. The regression coefficient at term of order two has strong dependence on aerosol optical thickness $<T_{a}(500)>$ measured with the sunphotometer Cimel CE-318 at $\lambda=500 \mathrm{~nm}$ : this coefficient decreases with increasing of the aerosol optical thickness. Coefficient at term of order one is practically independent on $\left\langle T_{a}(500)\right\rangle$, and free term is negligible one. 
Total column ozone trend gives the value of $\sim-10 \mathrm{DU} / \mathrm{decade}$. This value was derived from the multiyear (1978-2004) statistics of the TOMS measurements. Measurements of total column ozone made with MICROTOPS at the Kishinev site from September 2003 to August 2004, gave maximum and minimum values of daily means of ozone with $\sim 489$ DU (on February 12, 2004) and 259 DU (on December 3, 2003), respectively. Yearly mean value of total column ozone measured with ozonometer at the Kishinev site was $\sim 338$ DU.

\section{ACKNOWLEDGEMENTS}

I thank Dr. Brent Holben, the Principal Investigator of the AERONET program (NASA/GSFC) and his staff in supplying sunphotometer Cimel-318 used in this investigation at the Kishinev site and data processing. The work was funded by the U.S. Civilian Research \&Development Foundation (CRDF) and the Moldovan Research and Development Association (MRDA) through grant \#ME23033.

\section{REFERENCES}

1. Morys M., Mims III F.M., Hagerup S., Anderson S.E., A. Baker, J. Kia, T. Wallkup (2001) J. Geophys. Res., 106, 14573-14582.

1. Holben B.N. et al. (1998), Rem. Sens. Environ., 66, 1-16.

2. Eck T.F., Holben B.N., Reid J.S., Dubovik O., Smirnov A., O'Neill N.T., Slutsker I. and Kinne S. (1999) J. Geophys. Res., 104, 31333-31350.

3. Smirnov A., Holben B.N., Eck T.F., Dubovik O. and Slutsker I. (2000) Rem. Sens. Env., 73, 337-349. 